\title{
Editorial \\ Breaking down barriers: the importance of the stromal microenvironment in acquiring invasiveness in young women's breast cancer
}

\author{
Pepper Schedin ${ }^{1,2,3,4}$ and Virginia Borges ${ }^{1,2,3}$
}

\author{
${ }^{1}$ Department of Medicine, Division of Medical Oncology, University of Colorado Denver, 12801 East 17th Avenue, Aurora, CO 80045, USA \\ ${ }^{2}$ University of Colorado Comprehensive Cancer Center, University of Colorado Denver, 12801 East 17th Avenue, Aurora, CO 80045, USA \\ 3Young Women's Breast Cancer Translational Research Program at the University of Colorado Hospital, 12605 E. 16 Avenue, Aurora, CO 80025 , \\ USA \\ ${ }^{4}$ AMC Cancer Research Center, University of Colorado Denver, 12801 East 17th Avenue, Aurora, CO 80045, USA
}

Corresponding author: Pepper Schedin, pepper.schedin@ucdenver.edu

Published: 26 March 2009

Breast Cancer Research 2009, 11:102 (doi:10.1186/bcr2235)

This article is online at http://breast-cancer-research.com/content/11/2/102

(c) 2009 BioMed Central Ltd

See related research article by Ma et al., http://breast-cancer-research.com/content/11/1/R7

\begin{abstract}
Gene expression profiling was performed on laser captured breast stroma and epithelium obtained from 14 breast cancer patients. As with breast epithelium, of the stromal gene expression changes observed between normal tissue and invasive ductal carcinoma, greater than $90 \%$ occurred early, at the normal to ductal carcinoma in situ transition. Only $10 \%$ of stromal and $0 \%$ of epithelial genes were differentially regulated between non-invasive ductal carcinoma in situ and invasive disease. These data suggest that the majority of gene expression changes required for transformation occur early, prior to histological evidence of an invasive phenotype, the stroma cooperates closely with epithelium in this transformation, and for acquisition of the invasive phenotype, the stroma is dominant over the epithelium.
\end{abstract}

In the previous issue of Breast Cancer Research Xiao-Jun Ma and colleagues of the Dennis $C$ Sgroi laboratory report on a comparative analysis of global gene expression in the microenvironment of ductal carcinoma as it relates to the acquisition of invasiveness [1]. The authors utilize an approach that significantly reduces confounding signals in the data due to inter-patient variability by performing laser capture on breast tissue from 14 breast cancer patients with matched normal and tumor samples. The majority of the cohort was premenopausal (mean age 41 years), with estrogen receptor positive tumors $(78 \%)$ and ipsilateral nodal involvement (78\%). Thus, this study focuses on young women's breast cancer, an important but understudied subset that is associated with poor prognosis [2,3].

Previous work from this group showed that gene expression changes in epithelium occur prior to local invasion, as early as atypical ductal hyperplasia [2]. Surprisingly, no major changes in epithelial gene expression were identified between in situ and invasive cancers. The authors now confirm these earlier results and demonstrate that, like the epithelium, tumor stroma undergoes dramatic gene expression alterations early, at the transition from normal to ductal carcinoma in situ (DCIS). Over 3,500 stromal genes were identified to be differentially regulated in DCIS compared to normal, whereas only 305 stromal genes were differentially regulated with the transition to invasion. These observations highlight early events that occur prior to histological evidence of local invasion, and the co-dependency between epithelial cells and the stroma, in regulating tumor progression.

Another important contribution of this work is the identification of a stromal gene signature that marks the transition to local invasion. While only three epithelial genes were identified as differentially regulated between DCIS and locally invasive disease, 76 stromal genes were upregulated and 229 downregulated in invasive cancers compared to DCIS. These new data further challenge the epithelial cell-centric, multi-hit model of metastasis by demonstrating that it is a stromal gene signature, not an epithelial signature, that distinguishes pre-invasive from invasive cancer. In 2002 van 't Veer and colleagues [3] demonstrated the power of global gene profiling by showing for the first time that expression signatures of the primary tumor could predict risk of metastasis with high accuracy. The van't Veer study fundamentally undermined the prevailing hypothesis that metastasis is solely mediated by the acquisition of rare and rate limiting mutations within a minority of tumor cells [4].

$\mathrm{DCIS}=$ ductal carcinoma in situ; ECM, extracellular matrix. 
Subsequent studies have demonstrated that having a poor prognosis gene signature is not sufficient for metastasis, as many cancers with such signatures do not metastasize [5]. These studies and others helped re-awaken interest in the role of the tumor microenvironment in orchestrating the metastatic switch [6].

The paper by Xiao-Jun $\mathrm{Ma}$ and colleagues adds to an impressive list of recent gene expression studies designed to investigate the role of the tumor microenvironment in breast cancer [7-10]. Prior to the reporting of these gene profiling studies, a histologically defined fibrotic response referred to as tumor desmoplasia had been correlated with poor prognosis $[11,12]$. In the study by Xiao-Jun $\mathrm{Ma}$ and colleagues, the short chain collagen types $\mathrm{X}$ and VIII and fibronectin were upregulated four- to six-fold in stroma surrounding DCIS compared to adjacent normal stroma, implicating these extracellular matrix (ECM) proteins in cancer progression. Pre-clinical studies strongly support the hypothesis that collagens and fibronectin directly promote metastatic phenotypes in cancer cells. For example, fibronectin signaling through $\beta 1$ integrin was recently found to cause loss of tumor cell quiescence via phosphorylation of myosin light chain and cytoskeletal reorganization [13]. Thus, it was somewhat surprising when two independent studies, utilizing gene profiles identified from very disparate tissue samples, reported that ECM proteins associated with the fibrotic response, including fibronectin, collagens I, III, and VI, biglycan, fibulin 2, SPARC, and connective tissue growth factor were associated with improved survival [10,14]. Resolution of these apparent contradictory observations will require significant advancement in the ECM field, including additional functional characterization of the ECM constituents, such as the 26 genetically distinct collagen types identified to date. Improvements in our understanding of matrix assembly, cross-linking, signaling and turnover will be required as well.

Insight into why a tumor fibrotic ECM signature could have dual effects on survival prognosis may be provided by the list of stromal genes upregulated at the DCIS to invasion transition, as reported by Xiao-Jun $\mathrm{Ma}$ and colleagues. This transition was accompanied by increased stromal expression of the matrix metalloproteinases MMP-2, MMP-11 and MMP14. Further, these authors found that stroma of invasive tumors was associated with a strong immune response signature, consistent with a large body of literature revealing multiple mechanisms by which immune cells positively regulate tumor progression [15]. Given that fragments of ECM proteins are key attractants and activators of immune cells under pathological conditions, differential proteolysis of tumor ECM and subsequent recruitment of immune cells may discriminate between tumor fibrosis associated with good prognosis from poor prognosis. Global gene expression profiling studies have helped formulate these exciting hypotheses and will no doubt continue to challenge our assumptions about breast cancer initiation, invasion and metastasis, permitting us to make inroads into this disease in ways previously unimagined.

\section{Competing interests}

The authors declare that they have no competing interests.

\section{References}

1. Ma XJ, Dahiya S, Richardson E, Erlander M, Sgroi DC: Gene expression profiling of the tumor microenvironment during breast cancer progression. Breast Cancer Res 2009, 11:R7

2. Ma XJ, Salunga R, Tuggle JT, Gaudet J, Enright E, McQuary P, Payette T, Pistone M, Stecker K, Zhang BM, Zhou YX, Varnholt H, Smith B, Gadd M, Chatfield E, Kessler J, Baer TM, Erlander MG, Sgroi DC: Gene expression profiles of human breast cancer progression. Proc Natl Acad Sci USA 2003, 100:5974-5979.

3. van 't Veer LJ, Dai $H$, van de Vijver MJ, He YD, Hart AA, Mao M, Peterse HL, van der Kooy K, Marton MJ, Witteveen AT, Schreiber GJ, Kerkhoven RM, Roberts C, Linsley PS, Bernards R, Friend $\mathrm{SH}$ : Gene expression profiling predicts clinical outcome of breast cancer. Nature 2002, 415:530-536.

4. Bernards R, Weinberg RA: A progression puzzle. Nature 2002, 418:823.

5. Paik S, Shak S, Tang G, Kim C, Baker J, Cronin M, Baehner FL, Walker MG, Watson D, Park T, Hiller W, Fisher ER, Wickerham $\mathrm{DL}$, Bryant J, Wolmark N: A multigene assay to predict recurrence of tamoxifen-treated, node-negative breast cancer. $N$ Engl J Med 2004, 351:2817-2826.

6. Schedin P, Elias A: Multistep tumorigenesis and the microenvironment. Breast Cancer Res 2004, 6:93-101.

7. Allinen M, Beroukhim R, Cai L, Brennan C, Lahti-Domenici J, Huang H, Porter D, Hu M, Chin L, Richardson A, Schnitt S, Sellers WR, Polyak K: Molecular characterization of the tumor microenvironment in breast cancer. Cancer Cell 2004, 6:1732.

8. Chang HY, Sneddon JB, Alizadeh AA, Sood R, West RB, Montgomery $\mathrm{K}$, Chi JT, van de Rijn M, Botstein D, Brown PO: Gene expression signature of fibroblast serum response predicts human cancer progression: similarities between tumors and wounds. PLoS Biol 2004, 2:E7.

9. Beck AH, Espinosa I, Edris B, Li R, Montgomery K, Zhu S, Varma $\mathrm{S}$, Marinelli RJ, van de Rijn M, West RB: The macrophage colony-stimulating factor 1 response signature in breast carcinoma. Clin Cancer Res 2009, 15:778-787.

10. Beck AH, Espinosa I, Gilks CB, van de Rijn M, West RB: The fibromatosis signature defines a robust stromal response in breast carcinoma. Lab Invest 2008, 88:591-601.

11. Egeblad M, Littlepage LE, Werb Z: The fibroblastic coconspirator in cancer progression. Cold Spring Harb Symp Quant Biol 2005, 70:383-388.

12. Mueller MM, Fusenig NE: Friends or foes - bipolar effects of the tumour stroma in cancer. Nat Rev Cancer 2004, 4:839-849.

13. Barkan D, Kleinman H, Simmons JL, Asmussen H, Kamaraju AK, Hoenorhoff MJ, Liu ZY, Costes SV, Cho EH, Lockett S, Khanna C, Chambers AF, Green JE: Inhibition of metastatic outgrowth from single dormant tumor cells by targeting the cytoskeleton. Cancer Res 2008, 68:6241-6250.

14. Albini A, Mirisola V, Pfeffer U: Metastasis signatures: genes regulating tumor-microenvironment interactions predict metastatic behavior. Cancer Metastasis Rev 2008, 27:75-83.

15. DeNardo DG, Johansson M, Coussens LM: Immune cells as mediators of solid tumor metastasis. Cancer Metastasis Rev 2008, 27:11-18. 